\title{
Caries Prevalence and Treatment Needs of 12-Year-Old Children in the Islamic Republic of Iran
}

\author{
Anahita Momeni Medya Mardi Klaus Pieper \\ Department of Pediatric and Community Dentistry, Philipps University Marburg, Marburg, Germany
}

\section{Key Words}

Dental caries - Caries prevalence - Epidemiology •

Twelve-year-old children · Socio-economic status • Iran

\begin{abstract}
Objective: To assess the prevalence of dental caries and treatment needs of 12-year-old children living in Teheran and a rural area surrounding Esfahan. Subjects and Methods: A total of 1,102 pupils were examined clinically for caries according to WHO criteria. One calibrated dentist examined all children. Results: Of the children studied, $63.8 \%$ had sound permanent dentition, $9.9 \%$ had filled teeth and $26.3 \%$ needed treatment. The mean DMFT value found was 0.77 (DFS: 1.19). The D component was $58.7 \%$, the $\mathrm{M}$ component $3.4 \%$ and the $\mathrm{F}$ component $37.9 \%$. The levels of caries experience varied according to the child's residence. The teeth of children living in the rural area (mean DMFT: 0.38) were significantly less affected than those of children living in Teheran (mean DMFT: 1.1). In the capital city of Teheran, considerable differences related to social status were observed. The lowest DMFT values (0.74) were found in southern Teheran where the poorest people live. The highest caries experience was found in the middle-class social stratum. Conclusion: The results indicate that caries prevalence among 12-year-old children in the Islamic Republic of Iran is as low as in the developed countries of central Europe.
\end{abstract}

Copyright $\Subset 2006$ S. Karger AG, Basel

\section{Introduction}

The caries status of a number of Middle Eastern countries has been the subject of previous, generally small, investigations [1-5]. In the Islamic Republic of Iran only a few surveys concerning dental health had previously been made, and these only published a part of their data [6-9]. The aim of this study was to assess the prevalence of dental caries and the treatment needs of 12-year-old children living in Teheran, the capital of Iran, and in a rural area surrounding Esfahan. The relationship between caries experience and socio-demographic status was given special attention.

\section{Subjects and Methods}

\section{Sample}

The study was conducted from February to March 1999. It was approved by the Ministry of Health and the Ministry of Culture gave official permission to conduct the examinations. Subjects were identified from class lists supplied by the Ministry of Education.

Representative samples of 12-year-old children from Teheran and villages near Esfahan were examined. Both in Teheran as well as in the region around Esfahan, the samples were chosen randomly from the school lists provided by the official offices.

In the process, we assigned the Teheran pupils to various levels of social status depending on the location of their school. Group 1 comprised schools in the northern and the middle part of Teheran and represent the highest socioeconomic status. Pupils allocated to group 2 visited schools in the north-eastern part of the town and

\section{KARGER}

Fax +41613061234 E-Mail karger@karger.ch www.karger.com
Prof. Klaus Pieper

Philipps University Marburg, Department of Pediatric and Community Dentistry Georg-Voigt-Strasse 3

DE-35033 Marburg (Germany)

Tel. +496421286 6690, Fax +4964212866691, E-Mail pieper@med.uni-marburg.de 
Table 1. Caries experience in Iranian 12-year-olds

\begin{tabular}{|c|c|c|c|c|c|c|c|c|}
\hline Villages near Esfahan & 348 & $\begin{array}{l}0.38(0.82) \\
p<0.001\end{array}$ & $0.29 ; 0.46$ & $\begin{array}{l}0.70(1.73) \\
p<0.001\end{array}$ & $0.52 ; 0.89$ & 77.3 & 16.7 & 6.0 \\
\hline
\end{tabular}

Figure in parentheses are standard deviations; $\mathrm{CI}=$ confidence interval.

Table 2. Mean DMFT and DFS values in Teheran depending on socioeconomic status (SES)

\begin{tabular}{llllll}
\hline & Total & Mean DMFT & $95 \%$ CI & Mean DFS & $95 \%$ CI \\
\hline High SES & 322 & $1.14(1.49)$ & $0.97 ; 1.30$ & $1.60(2.30)$ & $1.34 ; 1.85$ \\
Medium SES & 138 & $1.76(1.92)$ & $1.43 ; 2.08$ & $2.53(3.39)$ & $1.96 ; 3.10$ \\
Low SES & 294 & $0.74(1.14)$ & $0.61 ; 0.87$ & $1.11(2.30)$ & $0.85 ; 1.37$ \\
\hline
\end{tabular}

Figures in parentheses are standard deviations; $\mathrm{CI}=$ confidence interval. represent the middle class and group 3 consisted of children in the schools in the southern area of Teheran. They represent the lowest social class.

In Teheran, two boys' and two girls' schools were chosen by lot from each of level 1 and level 3, and one boys' school and one girls' school from level 2. Thus a total of five boys' and five girls' schools representing the various socioeconomic classes and distributed from north to south were selected. From each of these schools, 70-80 pupils were chosen by lot for examination.

From the list of schools in the villages surrounding Esfahan, seven schools were randomly chosen in which we examined all 12year-old children. No differences between the socioeconomic status were made in this region.

The sample consisted of 1,102 pupils: 754 children from Teheran and 348 from villages in the rural area near Esfahan.

\section{Clinical Examination}

All children were examined by one calibrated dentist (M.M.) using the WHO system for caries diagnosis. The examination chairs were placed in the rooms in such a way as to ensure an adequate source of natural light while at the same time avoiding direct sunlight. Teeth were examined without drying, using a No. 4 plane mouth mirror and a dental explorer. Caries diagnosis was based solely on clinical examination, and only caries at or beyond the dentinal level was recorded. DMFT and DFS values were recorded. The intra-examiner reproducibilty was calculated on the basis of duplicate examinations of a group of children and yielded a kappa value of 0.978

\section{Data Management}

The findings were coded on special survey sheets, later transferred to a computer and processed using a special analysis pro- gram. The statistical evaluation was performed by means of the software package SPSS, version 11.5. Non-parametric tests (MannWhitney U test) were performed to compare the mean caries scores of various subgroups. The level of significance was set at $\mathrm{p}<0.05$.

\section{Estimation of Fluoride Content in Drinking Water}

According to the Iranian Ministry of Agriculture and Water, drinking water is not fluoridated. An analysis of water samples from Teheran and Esfahan revealed $0.21 \mathrm{ppm}(\mathrm{mg} \mathrm{F} / \mathrm{l})$ and $0.47 \mathrm{ppm}$ (mg F/l), respectively.

\section{Results}

Of the children studied, $63.8 \%$ were clinically caries free (DMFT $=0), 9.9 \%$ had filled teeth and $26.3 \%$ needed treatment. The mean DMFT value found was 0.77 (DFS: 1.19). The D component was $58.7 \%$, the $\mathrm{M}$ component $3.4 \%$ and the $\mathrm{F}$ component $37.9 \%$. The level of caries experience varied according to the child's place of residence. Children living in the rural area (mean DMFT: 0.38, mean DFS: 0.7) had significantly fewer affected teeth/surfaces than children living in Teheran (mean DMFT: 1.10, mean DFS: 1.59) (table 1). In Teheran, considerable differences related to social status were observed (table 2). In the high-class social strata the mean DMFT value found (1.14) was significantly $(\mathrm{p}=0.001)$ lower than the DMFT value in the middle socio-economic strata (1.76), 


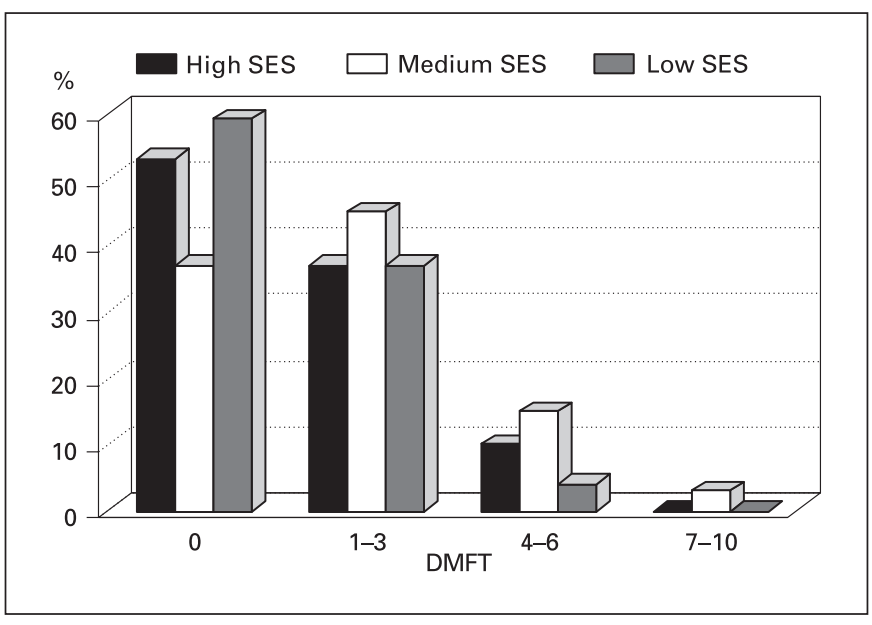

Fig. 1. Frequency distribution (\%) of DMFT values in Teheran according to socioeconomic status (SES).

Table 3. Breakdown of D, M and F components in Teheran in relation to diseased teeth

\begin{tabular}{lllr}
\hline & D & M & \multicolumn{1}{l}{ F } \\
\hline High SES & $158(43.0)$ & $5(1.4)$ & $205(55.6)$ \\
Medium SES & $143(58.9)$ & $9(3.7)$ & $91(37.4)$ \\
Low SES & $187(85.8)$ & $5(2.3)$ & $26(11.9)$ \\
\hline
\end{tabular}

Figure in parentheses are percentages.

which showed the highest caries experience in Teheran. The lowest DMFT value (0.74) was found in southern Teheran where the poorest people live and was significantly lower than the values found in the high SES ( $p=$ $0.003)$ and in the medium SES $(p<0.001)$. The frequency distribution (\%) of DMFT values in Teheran among the three different socio-economic strata is shown in figure 1.

The distribution of the $\mathrm{D}, \mathrm{M}$ and $\mathrm{F}$ components in the various social strata in Teheran is given in table 3 . Teeth extracted due to caries were extremely rare in all three social strata. The D and F components, however, differed considerably between the various social strata. The largest proportion of untreated carious teeth was found among children of low socioeconomic status $(85.8 \%)$, who also had the lowest number of filled teeth (11.9\%). Children of high socioeconomic status had the largest proportion of filled teeth $(55.6 \%)$.

\section{Discussion}

The mean DMFT observed in this study, 0.77 , shows that caries prevalence in 12-year-old Iranians currently falls within the 'very low' category (DMFT $<1.2)$ as defined by the World Health Organization [10], and is within the global goal of three or less decayed, missing or filled teeth at age 12 by the year 2000 .

Although caries experience is low, considerable differences between the social strata were observed.

As far as socioeconomic status was concerned, there are great differences between the north and the south of the city of Teheran. This is why we were compelled to assign the Teheran pupils to three different social strata according to their place of residence. The sociological instruments used in Western countries to determine socioeconomic status could not be applied to Iran.

Several studies have been conducted on the connection between oral hygiene and social status in industrialized countries. These studies all showed increased caries experience among the lower social classes [11-13].

In some developing and emerging nations, however, this situation is reversed. The caries experience in those countries is commonly higher in children of high socioeconomic status [14-17].

The results of the present study confirm this trend. This can perhaps be explained as follows: the upper classes can regularly afford sweets and beverages sweetened with sugar. This is at least partially offset by regular oral hygiene, in particular, the use of fluoridated toothpaste. There is only a limited range of oral hygiene products on sale in Iran. As a rule, Iranian children therefore use adult toothpaste, which has a higher fluoride content.

By contrast, the middle class can usually afford foodstuffs containing sugar, although awareness of oral hygiene is substantially lower in this class. It may be that not all children in this sample used fluoridated toothpaste, so that no topical fluoridation was performed. The lower class, however, is only rarely able to afford to buy or consume foodstuffs containing sugar. Since people in this socioeconomic stratum cannot afford beverages sweetened with sugar (soft drinks), they primarily drink tap water and black tea.

The fact that all social strata and age groups in Iran drink black tea along with their tap water could help explain the low caries prevalence in the population. A series of tests by Zhang and Kashket [18], for instance, proved that black tea inhibits up to $90 \%$ of the amylases in the oral cavity. The tannin contained in tea inhibits both salivary amylase as well as streptococcal amylase. The con- 
sequence is that starch breakdown is inhibited, thus giving rise to fewer low molecular weight carbohydrates that could provide the bacteria with a substrate [18].

Fluoridated table salt is not common in Iran, and is only rarely obtainable in special import stores. We found its market share to be less than $1 \%$. Hence there was no systemic fluoridation in this way.

The breakdown of specific DMF components in table 3 shows that the $\mathrm{D}$ and $\mathrm{F}$ components are differently distributed in the different social strata. Although people of low socioeconomic status exhibit the lowest DMFT scores, this is also the group with the highest number of carious DMF teeth and only $11.9 \%$ are provided with a filling. This trend is substantiated by a national study conducted in Iran in 1998-1999 [19] which also showed that children from poor and low-income families have a larger number of ruined teeth. This could possibly be because these children do not have ready access to oral health services, or because their parents are unable to pay for dental treatment.

Various studies have shown that caries experience rises as people live closer to a city [20-23]. Our results confirm this trend. This may well be explained by the fact that they have easier access to sugar [24-26]. Moreover, cities generally also tend to be the only places where a large selection of Western products (such as chocolate or soft drinks) can be found (and at high prices). In regions where diets are traditional and sugar consumption is low, dental caries tend to be less prevalent [27]. The teeth of populations which obtain their nourishment from a diet of natural foods requiring more strenuous chewing exhibit less damage [28].

The lower rate of decay experience in rural communities may also be due to the higher fluoride level in drinking water. A study conducted in Saudi Arabia found that 'among the primary schoolchildren there was a statistically significant difference in mean $\mathrm{dmft}$ scores at various fluoride levels of drinking water' [29].

To what extent is the consumption of fluoride in food of significance to the low prevalence of caries? To obtain accurate information, comprehensive data on children's dietary habits must be collected. A study done in 1999 calculated the concentrations of fluoride in various food groups in an Iranian province [30]. The same group of authors then studied the sources of dietary fluoride intake in 4-year-old children residing in areas where the fluoride content of the drinking water differed [31]. They discovered that, depending on the levels of fluoride in the water, the mean dietary fluoride intake was between 413 and $3,472 \mu \mathrm{g} /$ day. Drinks provided $72-87 \%$ of dietary fluo- ride. Tea was an important source of dietary fluoride. The study revealed that $80 \%$ of Iranian children drink tea routinely. Therefore, tea can contribute substantially to total fluoride intake. As already mentioned above, drinking black tea could well be the reason for this lower rate of caries experience.

Another important reason for the generally low DMFT scores in Iran could also be related to the areas on which the government has been focusing its efforts. The government has increasingly been promoting medical and dental care for the population and is in particular attempting to improve children's health by having doctors and dentists make regular visits to schools.

In the course of these developments, dental care has improved decisively. While there were 15,000 residents per dentist in 1990, this figure was only 5,500 in 2000 [32]. However, many Iranians have no health insurance. As a rule, visits to doctors and dentists must be paid for in cash. As a result, people with low incomes are only rarely able to take advantage of professional dental care.

\section{Conclusions}

The state of 12-year-old school children's caries experience in Iran can be assessed as surprisingly good compared with most developing countries.

Despite the good results, it is necessary to implement programs to maintain the low caries level, or even decrease it. Further national surveys are needed to assess the caries prevalence and treatment needs and to monitor potential oral health programs. 


\section{References}

1 Akpata ES, Al-Shammery AR, Saeed HI: Dental caries, sugar consumption and restorative dental care in 12-13-year-old children in Riyadh, Saudi Arabia. Community Dent Oral Epidemiol 1992;20:343-346.

-2 El Barbari M, Downer MC: Dental caries experience among 12-year-old children in the Gaza Strip. Community Dent Oral Epidemiol 1993;21:321-322.

$\checkmark 3$ Al-Dashti AA, Williams SA, Curzon ME: Breast feeding, bottle feeding and dental caries in Kuwait, a country with low-fluoride levels in the water supply. Community Dent Health 1995;12:42-47.

4 Al-Ismaily M, Al-Khussaiby A, Chestnutt IG, Stephen KW, Al-Riyami A, Abbas M, Knight M: The oral health status of Omani 12-yearolds: a national survey. Community Dent Oral Epidemiol 1996;24:362-363.

$\checkmark 5$ Al-Mohammadi SM, Rugg-Gunn AJ, Butler TJ: Caries prevalence in boys aged 2, 4 and 6 years according to socio-economic status in Riyadh, Saudi Arabia. Community Dent Oral Epidemiol 1997;25:184-186.

6 Farzine F: Statistics of oral and dental diseases in Dental Service of Amir-Aalam Hospital. Teheran, 1951, unpubl.

7 Nevitt GA: Report on a visit to Iran. Report EM/DENT/7 to WHO, 1959.

$>8$ Held AJ: A clinical survey about dental caries, periodontal diseases and oral hygiene in urban population in Iran. Parodontol Acad Rev 1967;1:159-192.

9 Seyedein SM, Zali MR, Golpaigani H, Yazdani H, Nourhalouchi S: Oral health survey in 12-year-old children in the Islamic Republic of Iran, 1993-1994. East Mediterr Health J 1998; 4:338-342.

10 World Health Organisation: Oral health global indicators for 2000. World Health Organisation, Geneva 1988.
11 Duenninger P, Pieper K: Mundgesundheitszustand und -verhalten in der Bundesrepublik Deutschland; in Institut der Deutschen Zahnärzte. Köln, Deutscher Ärzte-Verlag, 1991, pp 205-260.

12 Blinkhorn AS, Davies RM: Caries prevention. A continued need worldwide. Int Dent J 1996; 46:119-125.

13 Tickle M, Brown P, Blinkhorn A, Jenner T: Comparing the ability of different area measures of socioeconomic status to segment a population according to caries prevalence. Community Dent Health 2000; 17:138-144.

$\checkmark 14$ Enwonwu CO: Review of oral disease in Africa and the influence of socio-economic factors. Int Dent J 1981;31:29-38.

15 Olojugba OO, Lennon MA: Dental caries experience in 5- and 12-year-old school children in Ondo State, Nigeria in 1977 and 1983. Community Dent Health 1987;4:129-135.

16 Manji F, Fejerskov O: Dental caries in developing countries in relation to the appropriate use of fluoride. J Dent Res 1990;69:733-741.

$\checkmark 17$ Freire MCM, Melo RB, Silva SA: Dental caries prevalence in relation to socioeconomic status of nursery school children in Goiânia-GO, Brazil. Community Dent Oral Epidemiol 1996;24 357-361.

18 Zhang J, Kashket S: Inhibition of salivary amylase by black and green teas and their Effects on the intraoral hydrolysis of starch. Caries Res 1998;32:233-238.

19 Pakshir H: Oral health in Iran. Int Dent J 2004; 54:367-372.

20 Olsson B: Dental health situation in privileged children in Addis Ababa, Ethiopia. Community Dent Oral Epidemiol 1979;7:37-41.

21 Normark S: Social indicators of dental caries among Sierra Leonean schoolchildren. Scand J Dent Res 1993;101:121-129.
22 Irigoyen ME, Luengas IF, Yashine A, Mejia AM, Maupomé G: Dental caries experience in Mexican schoolchildren from rural and urban communities. Int Dent J 2000;50:41-45.

-23 Diehnelt DE, Kiyak HA: Socioeconomic factors that affect international caries levels. Community Dent Oral Epidemiol 2001;29: 226-233.

24 Chikte UM, Rudolph MJ, Smythe AE: Dental caries of 12- and 15-year-old schoolchildren in Gazankulu, South Africa. Community Dent Oral Epidemiol 1991;19:237-238.

-25 Mackeown TM, Cleaton-Jones PE, Hargreaves JA: Energy intake, dental caries and periodontal disease in 11-year-old black children in two regions of Southern Africa: KwaZulu and Namibia. Community Dent Oral Epidemiol 1995; 23:182-186.

26 Schier M, Cleaton-Jones P: Dental caries in Namibia - the first national survey. Community Dent Oral Epidemiol 1995;23:262-265.

27 Holm AK: Diet and caries in high-risk groups in developed and developing countries. Caries Res 1990;24:44-52.

28 Banoczy J: Ernährung und Plaque. Oralprophylaxe 1989;11:43-48.

$\checkmark 29$ Al Dosari AM, Wyne AH, Akpata ES, Khan $\mathrm{NB}$ : Caries prevalence and its relation to water fluoride levels among schoolchildren in Central Province of Saudi Arabia. Int Dent J 2004; 24:424-428.

30 Zohouri FV, Rugg-Gunn AJ: Fluoride concentration in foods from Iran. Int J Food Sci Nutr 1999;50:265-274.

31 Zohouri FV, Rugg-Gunn AJ: Sources of dietary fluoride intake in 4-year-old children residing in low, medium and high areas in Iran. Int J Food Sci Nutr 2000;51:317-326.

32 Pakshir H: Dental education and dentistry system in Iran. Med Princ Pract 2003;12(suppl 1):56-60. 